Research Journal of Applied Sciences 5 (3): 165-171, 2010

ISSN: $1815-932 \mathrm{X}$

(C) Medwell Journals, 2010

\title{
Health and Safety Management in University's Student Residential College: An Overview of Students' Perception and Awareness
}

\author{
${ }^{1}$ Kadir Arifin, ${ }^{1}$ Shaharuddin Ahmad, ${ }^{1}$ Kadaruddin Aiyub, ${ }^{1}$ Azahan Awang, \\ ${ }^{1}$ Lukman Z. Mohamad, ${ }^{1}$ Azmi Aziz, ${ }^{2}$ Samsu Adabi Mamat and ${ }^{3}$ Muhammad Rizal Razman \\ ${ }^{1}$ Faculty of Social Sciences and Humanities, University Kebangsaan Malaysia \\ 43600 UKM, Bangi, Selangor, Malaysia \\ ${ }^{2}$ Ungku Omar College, University Kebangsaan Malaysia, 43600 UKM, Bangi, Selangor, Malaysia \\ ${ }^{3}$ Institute of Environment and Development (LESTARI), Universiti Kebangsaan Malaysia, \\ 43600 UKM, Bangi Selangor Darul Ehsan, Malaysia
}

\begin{abstract}
This research studied students perception and awareness on occupational safety and health management in residential college. To achieve this objective, Ibrahim Yaakob College (KIY), University Kebangsaan Malaysia was chosen as a case study. Even though safety and health management aspects has been implemented through out the university, there are possibilities that students are exposed to certain types of accident and injuries. Therefore, it is important to carry out this study in order to ascertain to what extent the level of safety and health awareness among students at KIY. About 129 respondents were chosen among students who stayed at KIY. Pearson correlation method was employed to analyze the data. The result showed that various perceptions were given by respondents in relation to management level and occupational safety and health procedure at KIY. The study also found that there was a significant relationship between demographic factors and occupational safety and health training. Furthermore, the university should pay more attention to the aspects of safety and health management especially among residential college occupants, thus the welfare of the student can be managed properly.
\end{abstract}

Key words: Occupational safety, college management, residential college, college vicinity, student health level, environmental safety level

\section{INTRODUCTION}

Occupational Safety and Health (OSH) is an important procedure or program either in the government or private sectors now-a-days. The safety workplace will ensure the good health of the employees, thus enhance the productivities of the workers. On the other hand, if the workplace environment unsafe, it is not only it will affect human productivities but also will increase government and/or companies hospital or clinic bills as well as absence from work. Therefore, it is a duty of the organisation to acertain the implementation and practices of the occupational safety and health program in its organisation.

With regards to this matter, it is found that there are many studies have been carried out in many countries. For instance, studies have been conducted in relation to employees and public perception on occupational safety and health in Malaysian LNG, knowledge and occupational safety and health risk among managers and employees of blue collars in Australia (Holmes et al., 1998) and the perception of senior financal excutive or manager on the important of safety occupational environment issues in the United State of America (Huang et al., 2007).

Study was also conducted in New Zealand by Gurjeet et al. (2004) to analyse perception of the flying industry employees on the aspect of safety management. They found that safety culture was important to ensure the safety of employees as well as passengers of the flying company.

Research on occupational safety and health management aspects has gained attention by various researchers. Most of the studies such as Arifin et al., 2008, 2009a, b), Razman et al. (2009), Lee et al. (1998), Hovden et al. (2008), Haslam et al. (1998) and Riise et al. (2000) found that it was important for the management of the company/organization to conduct training, safety

Corresponding Author: Kadir Arifin, Faculty of Social Sciences and Humanities, University Kebangsaan Malaysia, 
exercises and regular monitoring of the safety and health procedures and programs. Moreover, there should be a good collaboration between manager and employee especially with respect to decision making on $\mathrm{OSH}$. Therefore, an effective management should always be associated with the thinking of how to acheive optimum safety and health of indivudual employee.

Awareness of the occupational safety and health aspects will enhance work or safety culture among public and private sectors worker, regardless their positions. Should this thinking happened in any organization, productivities of the organization will increase and clients will definately get a better service. These findings had been proven by several studies such as worked of Carroll (1998); Clarke (1999) and Petersen (1993).

Another aspect of $\mathrm{OSH}$ that attracks many researchers to study is accident prevention. In general, accident prevention should not only be centered on technical management of risk but also on the interaction processes where safety behavior and organization factor are present (Sese et al., 2002). Safety behavior is explained by environment, person, organization confluence, consequently, intervention programs should be prepared to enhance safety behavior (Chhokar and Wallin, 1984; De Pasquale and Geller, 1999; Lingard and Rowlinson, 1997; McAfee and Winn, 1989; Peters, 1991; Saarela, 1990; Kongtip, 2008).

In Malaysia, residential college or academic college as known in Universiti Kebangsaan Malaysia (UKM) is a temporary apartment provided by university for students while they are studying at university. In order to stay in college, students have to pay certain among of fee for each semester. The fee will cover for room charge, facilities and activities in college.

The academic college is headed by college master with normally supported by deputy college master. College manager will spearhead the college management which is responsible for maintenance of all college facilities. Apart from this, the implementation of the occupational safety and health prosedures and program is the college management responsibility. This is important to acertain the safety of the college residents while they stay in college.

In UKM, several occupational safety and health programs have been organized such as poster exhibition and video presentation. However, to what extent those efforts give an impact on safety and health awareness to students at colleges. Most of the programs organized by UKM are meant to increase safety and health awareness among staffs. Recently, due to awareness among college masters and the college management, safety and health program were conducted at various residential colleges, including Ibrahim Yaakob College (KIY). Therefore, this study attempts to research to what extent this occupational safety and health program will really benefit college residents, especially at KIY. It is also the aim of this study to analyse awareness among the residents of KIY on the Occupational Safety and Health (OSH) that is implemented at their college.

\section{MATERIALS AND METHODS}

Research was carried out to study respondents perception on program and/or procedure of occupational safety and health at Ibrahim Yaakub College (KIY). Table 1 shows the percentage distribution of respondents according to seven residential blocks at KIY.

Four blocks were occupied by male students and three blocks by female students. Altogether, there were 129 respondents or $20 \%$ out of the possible 649 students who stayed at KIY. The sample of respondents was equally chosen among male and female students.

A set of questionnaire was used as a tool to gather students perception and indicate thier level of awareness on safety and health aspects. The questionnaire was divided into seven sections. Section A was mainly on respondents background meanwhile questions on occupational safety and health program and aspect formed the sections $\mathrm{B}$ and $\mathrm{C}$, respectively.

Questions on safety and environment at workplace or residential college were designed in section $\mathrm{D}$ and sexual harassment in section $F$. The last section (Section G) was designed to gather respondents comments and suggestions on the safety and health program and procedure that was carried out at their residential college.

Simple statistical techniques were used to analyze the data such as percentage, mean score and pearson correlation coefficient. Analyzed data were then shown in the form of tables.

\begin{tabular}{lcc}
\multicolumn{3}{c}{ Table 1: The number of students and samples according to block at KIY } \\
\hline Blocks & $\begin{array}{c}\text { Total No. } \\
\text { of students }\end{array}$ & $\begin{array}{c}\text { No. of } \\
\text { samples }\end{array}$ \\
\hline K 14 male students & 129 & 26 \\
K 15 A male students & 35 & 6 \\
K 15 B male students & 39 & 8 \\
K 15 C male students & 36 & 7 \\
K 14 female students & 161 & 32 \\
K 13 A female students & 125 & 25 \\
K 13 B female students & 124 & 25 \\
Total : 7 block & 649 & 129 \\
\hline
\end{tabular}




\section{RESULTS AND DISCUSSION}

Background of the respondents: Table 2 shows the distribution of the respondents according to age cohorts. Majority of the respondents was fall in the age cohort of $21-23$ years old $(66 \%)$ and followed by the age cohort of $18-20$ years old $(28.0 \%)$. The higher number of respondents in the lower age cohort was due to the fact that more 1 st year students came from the matriculation class. This situation continued whereby reflected by the high percentage of the second age cohort. Most of the respondents in this age cohort were second and 3rd year levels.

Analysis was also carried out in terms of respondents year of study at University Kebangsaan Malaysia (UKM). It was observed that about $73 \%$ of the respondents that stayed at KIY were 1 st and 2nd year student, meanwhile the remaining percentage was formed by the $3 \mathrm{rd}$ and 4th year students. Further analysis was focused on the distribution of respondents according to faculty. About $31 \%$ of the respondents pursued their undergraduate degree at the Faculty of Science and Technology (FST), $29.4 \%$ at the Faculty of Social Sciences and Humanities (FSSK), $11.6 \%$ at the Faculty of Economy and Management (FEP) and $10 \%$ at the Faculty of Islamic Studies (FPI). The remaining percentage of the respondents studied at the Faculty of Technology and Information Science (FTSM), Faculty of Engineering and Built Environment (FKAB) and Faculty of Education (FPEN).

Knowledge of safety and health program among respondents: Six questions with regards to knowledge of safety and health program were put forward to respondents at KIY (Table 3). These questions attempted

\begin{tabular}{lc} 
Table 2: Percentage of respondents according to age cohorts & \\
\hline Age cohorts (years) & Percentage \\
$18-20$ & 28 \\
$21-23$ & 66 \\
$24-26$ & 4 \\
$27-29$ & 1 \\
$30-33$ & 1 \\
Total & 100 \\
\hline
\end{tabular}

Table 3: Percentage and mean score of students knowledge level on OSH Questions Yes $(\%)$ No (\%) Mean

Do you know about the college committee of occupational safety and health (COSH)?

Do you know UKM has occupational safety

$\begin{array}{lll}47 & 53 & 1.53\end{array}$

and health policy?

Have you ever seen the occupational safety and health policy display in college?

$\begin{array}{lllll}\text { Do you know the procedures in the occupational } & 29 & 71 & 1.71\end{array}$

safety and health act in relation to daily works?

Do you know the occupational safety and

health policy prepared by the college management?

Do you know that you are protected by the

Occupational Safety and Health Act? to find out to what extent that the level of knowledge of respondents about the program, campaign and training of Occupational Safety and Health $(\mathrm{OSH})$ that was carried out by the KIY management. Even though, quite a high percentage of the respondents knew about the existence of committee of occupational safety and health at the UKM level as well at the college, only small number of the respondents knew about the procedures of $\mathrm{OSH}$ at the workplace. Moreover, many of them did not know that the college management had prepared and displayed the $\mathrm{OSH}$ policy.

It is obvious from this finding that quite a high number of respondents in KIY did not bother about the development of occupational safety and health despite it was displayed at the notice board of the KIY general office. It implies that the effort of the college management to expose, educate and promote the OSH to the college residents has failed to meet the specified target. This can be attributed to the perception of the respondents that $\mathrm{OSH}$ Act is only meant for the attention of the college workers and not for the students attention. This is a wrong perception because students should also learn and pay attention to the $\mathrm{OSH}$ act whereby it can be applied and practiced in their daily life. In relation to this, therefore, many students did not know that they are protected by the $\mathrm{OSH}$ Act and they have the right to live at the safe college environment. Thus, students at KIY should know and be alert with any current college development regardless the subject matter. This is important for their well being while they stay at KIY.

Table 3 shows mean differences between six elements of evaluating the students knowledge on OSH at the KIY. Obviously, the procedures and policy of the OSH Act which were provided by the college management showed the higher mean score of 1.71 , meanwhile the other elements showed less mean scores.

In an attempt to find significant relationship between various variables of occupational safety and health and respondents perception, Pearson correlation (r) test were carried out. Firstly, we analysed the correlation between respondents years of study and their knowledge is anailsedabout the presence of college committee of Occupational Safety and Health (COSH). The result showed that the pearson correlation, $\mathrm{r}$ was 0.286 implying that there was a significant correlation between the two variables at the significant level of $\mathrm{p}<0.01$. Even though, the interviewed respondents were from different years of study, they had to know and should be told about the presence of college committee of Occupational Safety and Health $(\mathrm{COSH})$. This is important for all college residents to report and inform to $\mathrm{COSH}$ should emergency or accident occurred at college. 
Res. J. Applied Sci., 5 (3): 165-171, 2010

Table 4: Mean score of program, campaign and training of $\mathrm{OSH}$ as organized by the college management

\begin{tabular}{lccc}
\hline Questions & Yes (\%) & No (\%) & Mean \\
$\begin{array}{l}\text { Have you ever follow college campaign or } \\
\text { college program of safety and health training? }\end{array}$ & 77.5 & 22.5 & 1.22 \\
$\begin{array}{l}\text { Have you ever been explained about occupational } \\
\text { safety and health at the college (OSH)? }\end{array}$ & 24.1 & 75.9 & 1.76 \\
$\begin{array}{l}\text { Have you ever been involved in training } \\
\text { of OSH in the form of campaign and training }\end{array}$ & 31.1 & 68.9 & 1.69 \\
$\begin{array}{l}\text { program provided by college management? } \\
\begin{array}{l}\text { Have you ever been brief on OSH Act? } \\
\text { Mean total }\end{array}\end{array}$ & 14.0 & 86.0 & 1.89 \\
\end{tabular}

Secondly, the same test was carried out to find the relationship between an organized talk on OSH Act and frequency of attending occupational safety and health training. The $r$ value of 0.305 and calculated it was significant at the level of $\mathrm{p}<0.01$. This implies that the college management plays a significant role in informing and explaining the $\mathrm{OSH}$ Act and prosedure to residents regularly and frequently.

Thirdly, the relationship between respondents knowledge of the procedures in the occupational safety and health act and the occupational safety and health policy. The calculated $r$ value of 0.321 was statistically significant at the level of $\mathrm{p}<0.01$. It can be concluded that there was a good correlation between the two variables, implying that the level of awareness among respondents about the occupational safety and health policy and procedures at KIY was quite high.

Respondents involvement in the occupational safety and health program: Respondents showed their interest in attending any safety and health program or campaign organized by Ibrahim Yaakob college. It was clearly shown in Table 4 whereby about $78 \%$ of the respondents attended the safety and health program organized by the college. However, most of the respondents who attended the program were female students whilst male students seemed did not very keen to attend any such program and campaign. On the other hand, respondents who did not attend the program attributed this to the lack of safety and health promotion or advertisement.

From the survey, it is found that only about $14 \%$ of the respondents were ever been brief on OSH Act (Table 4). The reason gave by most of the respondents was that they preferred to take part in practical activities of occupational safety and health campaign or program rather than listening to talk and briefing on such program. Therefore, the survey found that only about $24.1 \%$ of the respondents attended the courses, workshops, seminar or exercises with respect to Occupational Safety and Health $(\mathrm{OSH})$. Furthermore, only about $31.1 \%$ of the respondents had ever been involved in training of $\mathrm{OSH}$ in the form of campaign and training program provided by college management. This finding could be due to two possible
Table 5: Mean score of respondents knowledge level on program and campaign of $\mathrm{OSH}$ conducted at $\mathrm{KIY}$

\begin{tabular}{|c|c|c|c|}
\hline Element & Yes $(\%)$ & No $(\%)$ & Mean \\
\hline $\begin{array}{l}\text { Do you know the college emergency telephone } \\
\text { number? }\end{array}$ & 33 & 67 & 1.67 \\
\hline Do you ever suffer from injury at college? & 12 & 88 & 1.88 \\
\hline $\begin{array}{l}\text { Do you know where to lodge report if accident } \\
\text { or emergency occur at college? }\end{array}$ & 71 & 29 & 1.29 \\
\hline $\begin{array}{l}\text { Do you know who is the incidence officer at } \\
\text { college? }\end{array}$ & 16 & 84 & 1.84 \\
\hline $\begin{array}{l}\text { Do you know that every accident or emergency } \\
\text { is considered serious by the block leader and } \\
\text { action should be taken immediately? }\end{array}$ & 69 & 31 & 1.31 \\
\hline
\end{tabular}

reasons; one was students attitude towards such program whereby they did not bother and take note on such program organized by the college management. The other reason was lack of promotion of the $\mathrm{OSH}$ by the college management (Table 3).

Study was also conducted to evaluate any significant differences between four elements of program, campaign and training of $\mathrm{OSH}$ as organized by the college management (Table 4). The highest mean score of 1.89 was calculated for question with respect to ever been brief on OSH Act. Respondents had been explained about the occupational safety and health came the second higher mean score i.e., 1.76. The lowest value of 1.22 was calculated for question about respondents ever follow college campaign or program of safety and health training.

Knowledge of respondents about the occupational safety and health program and campaign at college: Table 5 shows five mean scores of respondents knowledge level on program and campaign of OSH at KIY. The survey found that $67 \%$ of the respondents did not know about the college emergency telephone number. This could be the reason why the immediate action was slow in any case of emergency or accident that was involved the college residents. Even though the case of injuries such as cut and fall from staircase was small (only 12\%), it does not mean that residents of the KIY could simply ignore the college emergency telephone number. Therefore, it is the duty of the college management to inform, distribute and display the emergency telephone number to notify the residents as well as the staffs of the college. The good about only a few resident suffer from injury within the college vicinity means that safety and cleanliness at the college is at the level of satisfaction, thus providing safety environment for the college residents and staffs.

From the survey, we found that about $71 \%$ of the respondents knew where to lodge report if accident or emergency occurred at the college (Table 5). The result indicates that residents of the college were capable of handling any accident or emergency case at the college level. However, when we asked respondents about who was the college incidence officer, it was only $16 \% \mathrm{knew}$ 
Res. J. Applied Sci., 5 (3): 165-171, 2010

Table 6: Elements and mean score of respondents safety level at KIY

\begin{tabular}{lccc}
\hline Element & Yes (\%) & No (\%) & Mean \\
\hline $\begin{array}{l}\text { Do you feel tired when climb up stair at } \\
\text { college? }\end{array}$ & 75 & 25 & 1.25 \\
$\begin{array}{l}\text { Do you know there is extinguisher } \\
\text { equipment at KIY blocks? }\end{array}$ & 93 & 7 & 1.07 \\
$\begin{array}{l}\text { Do you know how to use extinguisher } \\
\text { equipment? }\end{array}$ & 64 & 36 & 1.36 \\
$\begin{array}{l}\text { Do you know that there are emergency stairs } \\
\text { that can be used if fire broke at KIY? }\end{array}$ & 66 & 34 & 1.34 \\
\hline
\end{tabular}

the person, hence create concerned to college management. This finding is due to the fact that the incidence officer himself did not take any measure to introduce himself to residents of the college. It is necessary for the college management to take action such as to display the photo of the incidence officer at the strategic places. It is also important for the incidence officer to regularly inspect the college blocks with uniform on so that it makes known the presence of him as the incidence officer of the college.

The survey was also conducted to find whether or not the respondents agreed with the present emergency plan at the college and should accident or emergency cases occurred at the vicinity of the college, then immediate action must be taken by block leader. The survey found that more than half of the respondents (69\%) agreed with the question. This implies that the knowledge about the occupational safety and health is very important to residents of KIY especially for block leaders. This know-how will help them how and where to take residents involve with accident or emergency within the college vicinity. Nonetheless, the remaining $31 \%$ of this question is considered quite high whereby the college management should seriously pay attention to this problem if the college plan to see the occupational safety and health program sucessful at KIY.

Further analysis was carried out to find the mean score of the five elements (Table 5). It was found that three out of five elements showed high mean scores i.e., above 1.50. The three elements were respondents ever suffer from injury at college (1.88); respondents recognized the incidence officer at college (1.84) and respondents knew college emergency telephone number (1.67). The lowest mean score was calculated for the respondents knowledge where to lofge report if accident or emergency occur at KIY (1.29).

Respondents safety level at the college: Study was also carried out to find the safety level of respondents at KIY (Table 6). Respondents were asked four elements with respect to safety level at college. The result showed that $75 \%$ of the respondents answered that they were tired when climbed up stair at college. One of the reasons was
Table 7:Percentage and mean score of environmental safety level at KIY

\begin{tabular}{lccc}
\hline Questions & Yes (\%) & No (\%) & Mean \\
\hline Do you feel safe when walking on watery areas? & 10 & 90 & 1.90 \\
Are furnitures at KIY safe to be used? & 82 & 18 & 1.18 \\
Do you think electrical plugs in rooms are safe? & 85 & 15 & 1.15 \\
Do you think electrical switch in rooms are safe? & 88 & 12 & 1.12 \\
Do you think corridoor lights are bright? & 72 & 28 & 1.28 \\
Do you ever use plug in the rest room? & 37 & 63 & 1.63 \\
Do you know any outside intruder to KIY? & 48 & 52 & 1.52 \\
Do you ever experience sexsual harassment? & 11 & 89 & 1.89 \\
\hline
\end{tabular}

attributed to the location of the college at the top the hill. This geographical factor played an important part in $\mathrm{OSH}$ aspects. Moreover, the width of staircase used by residents as the commute path from and to college is quite narrow. Respondents were also felt that every step of the staircase was narrow, thus difficult for them to climb up and down the staircase. This scenario contributed to unsafe condition to residents.

With regard to extinguisher equipments at KIY, the responses of the interviewed respondents were very convincing because almost all knew the existence of it and how to use the equipments (Table 6). Therefore, as far as the extinguisher equipments-safety level relationship is concerned, the college management should not be worried very much in terms of informing and educating the residents about the fire procedure at college. This situation is supported by the next question been asked to respondents i.e., the knowledge about the emergency stairs at college. More than half of the respondents (66\%) knew where and how to use the emergency stairs in the case of fire at the college vicinity.

When out further analysis are carried out to determine the mean scores of the four elements, it is found that only one element had produced low mean score i.e., the knowledge of the existence of extinguisher equipments at college (1.07). The higher mean score was calculated for the knowledge how to use extinguisher equipment (1.36).

Environmental safety level at the college: Table 7 shows the percentage and mean score of environmental safety level at KIY. About 8 questions were formulated and put forward to respondents. It is found that more respondents felt that they were not safe when walking on the watery or slippery areas $(90 \%)$. For example, most of the toilets were almost very wet and slippery at all time. Therefore, they have to be very carefull when going in and out of the toilet. They attributed this problem to the daily toilet maintenance whereby the toilet floor was cleaned irregular and sometime only once a day.

In terms of furniture provided by the college management, most of the respondents (82\%) satisfied with the condition and felt quite safe. However, from the observation at several college rooms we found that many 
of the furniture structure such as tables are very unsafe to residents. This is because of sharp and dangerous corners or angles. Should residents accidently hit the sharp corners of the table, this could cause bruise, cut or harmful to them. Therefore, it is advisable for the college management to take future measure about this problem to ensure residents' safety within indoor environment.

Further survey was carried out to find respondents perception about the safety of the electrical appliances at KIY such as electrical plugs and switches in individual room. It showed that $>80 \%$ of the respondents satisfied with the presence conditions of electrical plugs and switches, meaning that the appliances were perfect and safe to be used by the college residents (Table 7). However, the observation at the college premises found that there were a few plugs and switches could be considered as inperfect conditions. This condition could trigger electrical short circuit as well as electric spark, hence dangerous to residents of the college. Furthermore, it could put college on fire and thus treatening residents'life and college properties. Even though, there are no inccidents and complaints from residents with regards to serious electrical problems, the management of the college, especially the maintenance division should regularly check all the electrical appliances in order to prevent any unnecessarily incidents happen in the college premises.

Another important aspect of the occupational safety and health element is the incidence of outside intruder to KIY. When we put forward this question to respondents, $48 \%$ of them said that they used to experience their rooms were broken in by outside intruders. This is a significant percentage that enough to be worried by the college management. The intruders in desperate situations could do anything to escape including cause serious harmful to residents. In relation to this problem, female respondents are futher asked if they ever experienced sexsual harassment in KIY. Even though, it was only $11 \%$ of the respondents ever experienced sexsual harassment, the problem still exist in the college premises that really needs stringent measures from the college management. From the observation, most of the contract workers within the college vicinity to carry out maintenance jobs did not accompanied by the college staff. Therefore, the workers can do what ever they like besides their official duty at the college. The college management should check and strictly imposed regulation to outside workers to wear name tag when ever they are in the college premises.

Respondents health level at the college: In an attempt to study health level of the KIY residents, It is conducted survey with respect to the state of college cafe hygiene
Table 8: Percentage and mean score of respondents safety level at KIY

\begin{tabular}{lccc}
\hline Questions & Yes $(\%)$ & No $(\%)$ & Mean \\
\hline Do you experience food poisioning? & 15 & 85 & 1.85 \\
Is the food quantity at KIY enough? & 38 & 62 & 1.36 \\
Do you ever feel sick at KIY? & 76 & 24 & 1.62 \\
Do you go to UKM Health Center? & 60 & 40 & 1.40 \\
Do you go to private clinic? & 17 & 83 & 1.83 \\
\hline
\end{tabular}

including food preparation (Table 8). It is found that food preparation was good as reflected by a small number of respondents experienced food poisioning after eating meal from the college cafe (15\%). Even though, it was less residents suffered from food poisioning, there are rooms for the college café management to improve their food quality. If the college cafe owner takes proper measure to improve food quality as well as hygiene of the surrounding environment, then the safety and health level of the whole college will be guaranteed.

Further question was put forward to respondents with respect to food quantity served by the college cafe. Majority of the respondents (62\%) felt that the food quantity was not enough and not reasonable for the sum of money they spent. Therefore, they had to spend more money to get enough food for their daily meals.

When the health level of the respondents with investifated respect to sickness, it is found that $76 \%$ has experiened sickness while at KIY. The survey found that respondents were experienced sickness such as food poisioning, headache and fever. However, there was no evident that these health problems especially headache and fever were due to state of food quality provided by the college cafe. Therefore, it is believed that other factors play their significant roles such as heavy workloads, less excersises not enough sleep and tigh daily programs.

\section{CONCLUSION}

In conclusion, the awareness and perception about the introduction and application of the occupational safety and health program that is organised by the KIY management are very much depending on the acceptance of the individual respondents. They have their own opinions whether the program has positive or negative values and has impact on their daily life while staying at college. In general, this study found that majority of the respondents knew and aware of the exixtence of OSH in their respective college. In fact, many of the interviewed respondents had followed and attended some of the programs organized by the college management. Even though a few of them did not recognize the incidence officer, they new where to lodge report if accident or emergency occurred within the college vicinity. Furthermore, respondents felt that emergency or accident are serious aspects to be considered thus block leaders 
should take immediate action to prevent any unnecessary outcome. However, the sucessful of the OSH program is also very much depending on the cooperation of all parties; college management, residents, college staffs and the university management.

It is advisable for the college management headed by college master to regularly monitor and organize $\mathrm{OSH}$ programs for the college residents, hence expose them to any aspect of $\mathrm{OSH}$ that should be implemented and practiced in KIY.

\section{ACKNOWLEDGEMENT}

This study was funded by University Research Project UKM-GUP-KRIB-17/08.

\section{REFERENCES}

Arifin, K., J.M. Jahi, M.R. Razman, K. Aiyub and A. Awang, 2009a. OHSAS 18001 vs implementation cost: Risk that will be faced by organization management in Malaysia. Soc. Sci., 4: 332-339.

Arifin, K., K. Aiyub, A. Awang, J.M. Jahi and R. Iteng, 2009b. Implementation of integrated management system in Malaysia: The level of organization's understanding and awareness. Eur. J. Sci. Res., 31: 188-195

Arifin, K., M.R. Razman and J.M. Jahi, 2008. Exploring the malaysian occupational safety and health act 1994. As a tool to control industry accident at workplace. Environ. Res. J., 2: 159-166.

Carroll, J.S., 1998. Safety culture as an ongoing process: Culture surveys as opportunities for enquiry and change. Work Stress, 12: 272-284.

Chhokar, J.S. and J.A. Wallin, 1984. Improving safety through applied behavior analysis. J. Saf. Res., 15: 141-151

Clarke, S., 1999. Perception on organizational safety: Implications for the development of safety culture. J. Organiz. Behav., 20: 185-198.

De Pasquale, J.P. and E.S. Geller, 1999. Critical success factors for behavior-based safety: A study of twenty industry-wide application. J. Saf. Res., 30: 237-249.

Gurjeet, K., G.K. Gill and G.S. Shergill, 2004. Perceptions of safety management and safety culture in the aviation industry in New Zealand. J. Air Transp. Manage., 10: 233-239.

Haslam, R.A., D.E. Gyi and A.G.F. Gibb, 1998. Case studies of occupational health management in the engineering construction industry. Occup. Med., 48: $263-271$.
Holmes, N., S.M. Gifford and T.J. Triggs, 1998. Meanings of risk control in occupational health and safety among employers and employees. Saf. Sci., 28: 141-154.

Hovden, J., T. Lie, J.E. Karlsen and B. Alteren, 2008. The safety representive under pressure: A study of occupational health and safety management in the Norwegian oil and gas industry. Saf. Sci., 46: 493-509.

Huang, Y.H., T.B. Leamon, T.K. Courtney, P.Y. Chen and S. De Armon, 2007. Corporate financial decision-makers' perceptions of workplace safety. Accid. Anal. Prev., 39: 767-775.

Kongtip, P., 2008. Occupational health and safety management in small and medium- sized enterprises: An overview of the situation in Thailand. Saf. Sci., 46: 1356-1368.

Lee, C.C., S.C. Hu, J.S.C. Shiao and Y.L. Guo, 1998. Employers awareness and compliance with occupational health and safety regulations in Taiwan. Occup. Med., 48: 17-22.

Lingard, H. and S. Rowlinson, 1997. Behavior based safety management in Hong Kong's construction industry. J. Saf. Res., 28: 243-256.

McAfee, R.B. and A.R. Winn, 1989. The use of incentives/feedback to enhance workplace safety: A critique of the literature. J. Saf. Res., 20: 7-19.

Peters, R.H., 1991. Strategies for encouraging selfprotective employee behavior. J. Saf. Res., 22: 53-70.

Petersen, D., 1993. Establishing good safety culture helps mitigate workplace dangers. Occup. Health Saf., 62: $20-24$.

Razman, M.R., A.S. Hadi, J.M. Jahi, K. Arifin and K. Aiyub et al., 2009. The legal approach on occupational safety, health and environmental management: Focusing on the law of private nuisance and International Labour Organisation (ILO) decent work agenda. Int. Business Manage., 3: $47-53$.

Riise, T., S. Torp and B.E. Moen, 2000. Systematic health, environment and safety activities: Do they influence occupational environment, behavior and health. Occup. Med., 50: 326-333.

Saarela, K.L., 1990. An intervention program utilizing small groups: A comparative study. J. Saf. Res., 21: 149-156.

Sese, A., A.L. Palmer, B. Cajal, J.J. Montano, R. Jimenez and N. Llorens, 2002. Occupational safety and health in Spain. J. Saf. Res., 33: 511-525. 